\title{
NOTES ON TRETANORHINUS OF CUBA AND THE ISLE OF PINES
}

\author{
BY CHAPMAN GRANT
}

\section{INTRODUCTION}

The first specimens of Tretanorhinus I had ever seen were those I described from Grand Cayman. The question was whether they were closer to Cuban or mainland forms. The key of Duméril and Bibron, Vol. 7, p. 349, showed that they were closer to the Cuban form. Dr. Barbour kindly sent me a Cuban specimen which he said was a "good typical example." When this specimen arrived it was seen to differ in color and pattern from the Grand Cayman specimens which I described (Grant, 1940, p. 46) as "differing in pattern and color only" from the Cuban form. While the Cayman paper was in press, Mr. Adrian Vanderhorst arrived from Cuba with a small herpetological collection. He presented me with his only specimen of Tretanorhinus, which was indistinguishable from the Cayman form except for color differences. Since Barbour and Ramsden $(1919$, p. 193) say that "this species is remarkably uniform in colouration ....,"I decided that there must be more than one species in Cuba of which they had seen only the one with uniform coloration. I had been planning another collecting trip to the Antilles and this prompted me to visit Cuba. At, about this time I heard of Congdon Wood's paper (1939) on this topic. Close reading of his paper made it clear that there was still something to be learned. The trip was cut short by the beginning of the War, but I was nevertheless able to collect the series of 59 specimens which is treated herein. The series was taken on the property of the Central Soledad near Cienfuegos, Santa Clara, Cuba, from January 13-23, 1942.

The material available at present in museums is insufficient to satisfactorily delimit subspecies. Mr. Wood's classification was largely based on color and markings, which might have been sufficient if his series had been large. The establishment of a subspecies based on the color of four specimens is hardly convincing, especially when some of the material in museums was originally preserved or set in formalin. Specimens frequently have insufficient ecological data. For instance, all of my series were taken on the Soledad properties in fresh water streams except one which was taken in a tidal estuary. This one brackish water specimen represents a separate species. The average label would not have differentiated the environment of this from that of the others, nor would the catalogue necessarily have made the distinction.

Probably one or more species and or several subspecies of Tretanorhinus 
inhabit Cuba and the Isle of Pines. When the problem is carefully worked out, the boundaries will doubtless coincide with ecological factors more than with the present vague geographical divisions.

Possibly some modification in nomenclature should be made in Wood's review of the genus in Cuba and the Isle of Pines. Wood uses preoculars, number of scale rows, light or dark venter, spots or crossbands as diagnostic characters. I endeavor to show that in my series, variation in preoculars and spots and bars are largely sexual manifestations and that the color of the venter is individual.

\section{SYNONYMY}

T. insulae-pinorum Barbour, probably a synonym.

Probably T. insulae-pinorum Barbour, is a synonym of T. wagleri (Jan), both being 21 scale row snakes. Barbour $(1916$, p. 306) gives the two following contradictory descriptions:

"Tretanorhinus insulae-pinorum. sp.nov. This species differs from the Cuban T. variabilis in having regularly 21 instead of 19 rows ... I have examined 3 examples... The series of 9 Cuban examples... have 19 rows ... There do not seem to be other differences in squamation and the color is the same so far as one may judge from Mr. Link's material preserved in formalin...."

Barbour reverses this diagnosis (1937, p. 154):

"This species [T. variabilis insulae-pinorum ${ }^{1}$ seems to have regularly 19 rows of scales while the Cuban snakes have 21 . This is, at first sight, a trivial character but one which is apparently really diagnostic."

Wood (1939, p. 7) lists M.C.Z. No. 12,285, T. v. insulae-pinorum, as having 20 scale rows. I would have expected that it was really a 21 row snake since an even number of rows is not normal in this species. $\mathrm{Mr}$. Loveridge kindly checked and reported that it had 19 rows. This individual may be an exception, abnormal, a specimen of another species or the labels may have become mixed. This is discussed later.

In Cuba there are snakes with 19 and 21 scale rows, which might account for Barbour's change of diagnosis, but I believe that the original description giving 21 rows is probably correct for the Isle of Pines freshwater population.

\section{Tretanorhinus variabilis wagleri (Jan)}

1865 Helicops wagleri Jan, Arch. Zool. Anat. Phys., Vol. 3, p. 247: Icon. Gen., Vol. 28, pl. 1. fig. 1, 1868.

${ }^{1}$ Barbour reduced his $T$. insulae-pinorum species to subspecific rank not because of any additional evidence of intergradation, but, as he says, merely to designate relationship. 
1916 Tretanorhinus insulae-pinorum Barbour, Ann. Carnegie Mus., Vol. 10, pp. 306-307; Zoologica, Vol. 11, p. 110, 1930; idem. Vol. 19, p. 134, 1935; and Loveridge, Bull. M.C.Z., Vol. 49, p. 351, 1929.

1937 Tretanorhinus variabilis insulae pinorum Barbour, Bull. M.C.Z., Vol. 82, p. 154.-Wood, Proc. New England Zool. Club., Vol. 18, p. 6.

1939 Tretanorhinus variabilis wagleri Wood, Proc. New England Zool. Club., Vol. 18, p. 7.

Type.-Unknown to writer.

Diagnosis.-A fresh water form from the Isle of Pines and western Cuba, intergrading at some place or zone with T.v. variabilis. Females usually, and possibly constantly, with 21 rows; tail as much as 10 caudals longer than in variabilis variabilis; color pattern with possible minor differences.

Tretanorhinus variabilis variabilis Duméril \& Bibron

1854 Tretanorhinus variabilis Duméril \& Bibron, Vol. 7, p. 349, pl. 80, fig. 4.-Cope, Proc. Acad. Phila., p. 298, 1861; idem. p. 309, 1868.Jan, Arch. Zool. Anat. Phys., Vol. 3, p. 254, 1865.-Gundlach, Erp. Cub., p. 80, 1880.-Bocourt, Le Natur., p. 122, 1891.-Boulenger, Cat. Sn. Brit. Mus., Vol. 1, p. 282, 1893.-Barbour, Mem. M.C.Z., Vol. 44, p. 330, 1914; idem. Vol. 47, pp. 192-194, 1919; Zoologica, Vol. 11, p. 110, 1930; idem. Vol. 19, p. 134, 1935.

1861 Tretanorhinus cubanus Gundlach, Mon. Berlin Ac., p. 1001; Erp. Cub., p. 81, 1880.-Bocourt, Miss. Sci. Mex. Rept., p. 795, 1895.

1865 Tretanorhinus variabilis var adnexus Jan, Arch. Zool. Anat. Phys., Vol. 3, p. 247.-Bocourt, Le Natur., p. 208, 1891.

1883 Helicops variabilis Garman, N. Am. Rept., p. 33.

1937 Tretanorhinus variabilis variabilis Barbour, Bull. M.C.Z., Vol. 82, p. 154.-Wood, Proc. New England Zool. Club., Vol. 18, p. 9, 1939. 1939 Tretanorhinus variabilis adnexus Wood, loc. cit., p. 8.

Type.-Paris Museum.

Diagnosis.-A fresh water form from the eastern part of Cuba; 19 scale rows counted behind neck; subcaudals, male not over 70 , female 54; color similar to T. v. wagleri; intergrading with wagleri at an undetermined place or zone.

\section{Tretanorhinus gaigeae sp. nov.}

Type.-Male, No. 60 Grant Cuban Coll., C. Grant coll., in brackish tidal estuary at Rancho Gavilan, Cienfuegos, Cuba; Jan. 18, 1942; adult male.

Diagnosis.-Upper parts light gray; 19 scale rows counted behind neck; small dorsal spots or saddles instead of crossbars as in variabilis; a con- 
tinuous dark line between ventrals and first row; first, second and part of third rows cream color; a broken black line on upper part of third row; above this, gray. Color and markings not approached by any specimen in a series of 58 specimens of variabilis.

Description.-Squamation as in v. variabilis; ventrals 154 , caudals 68 , preoculars 2-2, loreals $1-1$; body $581 \mathrm{~mm}$., tail $175 \mathrm{~mm}$.; belly cream colored, finely speckled with brown; 34 dorsal spots neck to sacrum, about 20 on tail.

Wood says of M.C.Z. No. 12, 285: "Nueva Gerona, is gray, with crossbars for the most part broken into small spots, resembling the mainland nigroluteus in this respect. Dark lines on first and fourth rows, the latter broken into spots posteriorly. Second and third rows cream colored. Below brown, speckled with white. Upper half of rostral, internasals, prefrontals and temporals light cream colored. Frontal dark brown; parietals light brown, finely speckled with black. This specimen with its extremely odd color pattern and unique scalation is probably no more than a freak."

Both specimens are males and it is possible that the female has 21 scale rows. Dr. Dunn examined my No. 60 and said that he was impressed with the difference in color.

\section{DISCUSSION of Tretanorhinus v. variabilis D. \& B. Habits}

At the time of my visit to Cuba, Dec. 13-23, 1941, it was very dry. Many of the smaller streams were a succession of puddles swarming with small fish which were being preyed upon by birds, crabs and snakes. The snakes were in turn being mutilated and even killed and eaten by the crabs. Many snakes were taken which had old or fresh scars on various parts of the body. The snakes come out of hiding about an hour after dark and start hunting fish. Snakes taken as late as 10 P.M. contained little food, but those found in the mornings resting on the mud under rocks or debris were full of fish. The snakes are quiet, easily caught and make no attempt to bite, but once frightened they show great agility in hiding. When taken by hand one characteristic is at once noticed at variance with the habits of most snakes: they grasp one's wrist with their tails with considerable force. A specimen can hold up the weight of its body if its tail is allowed to grasp one's finger. The nocturnal habits of this snake are attested by the vertically elongated pupil. There were no enlarged ova, but the knobbed scales on head, neck and region of the vent of males were prominent, a modification which is apparently permanent after maturity.

Barbour (1914, p. 330) says "It is a strictly aquatic snake which never leaves the water. .. It is a difficult species to find." (1916, p. 306) "The catibo leads a colorless existence... The members of this genus are the 
most strictly aquatic reptiles I know, quite equalling the Hydrophids in this respect. I have never heard of their eggs being found, and I have often wished I knew whether they come ashore to lay. I presume that they do."

\section{Scale Rows}

Serpents have probably undergone a general reduction in the number of body rows through modification of the body itself while evolving from a lizard-like form. The head of the snake is therefore the most logical place to look for remnants of lost rows since it has changed less than the body. Every neck scale or scale bordering the head-plates may have some significance although not always possible of interpretation. On the other hand there are cases among serpents where the number of body rows has increased with an increase of body size. This reversal of the general evolutionary trend is to meet some obscure mechanical law correlating the size of the scale and consequently the number of rows to the size of the snake. The correlation varies in different genera also due to obscure reasons connected with ecological factors and physical characteristics or manner of locomotion of the genus. Typhlops reduces by dropping a ventral row next the center; an indication of the order in which other serpents have lost their midventral suture. In the case of divided anals or preanals in Tretanorhinus the preceding ventral projects an angle posteriorly in an attempt to cover the suture. When a snake is found to have more rows at midbody than at the anterior part of the body it is probable that a short neck row occupies the same relative position as the added row.

Dr. Dunn points out that the hooded cobra's numerous neck rows may be a result of the hood and not representative of primitive body rows.

I have elsewhere (Grant, 1937) discussed the probable non-existence of a "midventral" row in reptiles except in snakes. The middorsal row may have had a different origin from the body rows. It may have originated with callosities, scutes or spines covering the vertebral processes as is now seen in the crests of lizards. It possibly did not develop from a fusion of the two highest body rows. The spiny crests of lizards are usually interrupted or reduced at neck and sacrum as is the spinal or vertebral row in snakes.

Ruthven (1908, pp. 16-21) found that the first rows to be dropped in Thamnophis were about midway between the ventrals and the spinal and were dropped in a fixed order somewhere near the middle of the body. Blanchard (1921, p. 10) stated that Natrix did the same.

Tretanorphinus, however, drops the paravertebrals at about the 100th ventral plus or minus ten, but apparently without dropping the fourth or fifth rows. 
I have written on the origin of the rows on the head of Natrix (Grant, 1935, p. 927) pointing out that frequently two rows start at the juncture of the parietals and extend only a short distance when the spinal or vertebral row appears. The spinal row does not appear to be a fusion product of the two dropped rows (see fig. 1.). Thus the paravertebrals are dropped by all three genera, but at widely different places.

Natrix and Thamnophis drop rows 4, 5 and 6 in a fixed order at about midbody. There is no such reduction apparent in Tretanorhinus until the neck is examined when it is seen that there is a short fourth row which
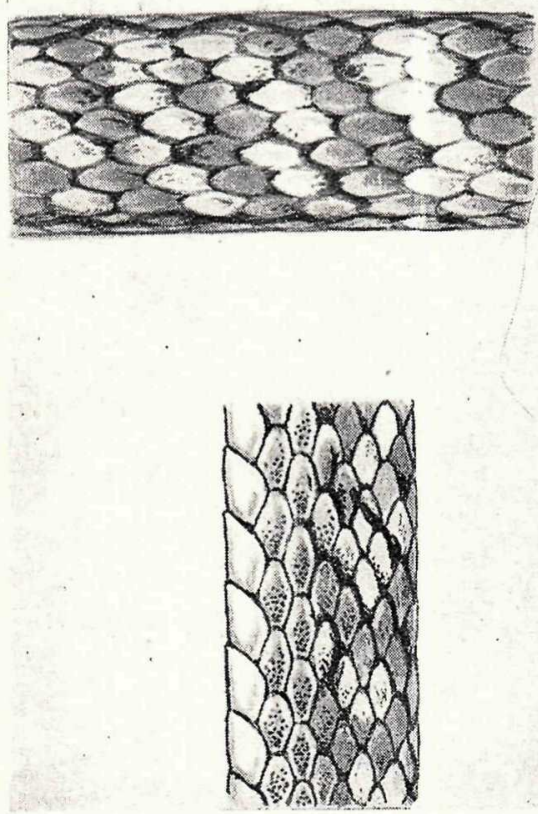

Frg. 1. Squamation of head of Natrix sipedon showing origin of scale rows.

stops at about the twelfth ventral. Thus the three genera seem to drop the same rows, but at widely different places.

To recapitulate: Natrix shows rudimentary paravertebrals and drops fourth etc. at about midbody. The "19 row" Tretanorhinus drop the paravertebrals at about midbody and the fourth row is rudimentary. Therefore one might expect to find that the "21 row" Tretanorhinus extended the 4 th row to about midbody.

The very first 21 -row snake examined from the U. S. N. M., No. 27,980 carried out this expectation. The $4 \mathrm{R}$ drops at 72 and the $4 \mathrm{~L}$ at 18 . This seemed to show a direct similarity between the genera in this respect, ex- 
cept for the fact that all the other U. S. N. M. 21-row specimens examined did no such thing; they drop the 10 th and 9 th rows.

This brings up the possibility that larger series may prove that there are two species; one dropping the 10th and 9 th and having a rudimentary 4th and another species which drops the 10th at midbody and the 4th also at midbody.

My Soledad series are all 19-row snakes as commonly understood. However, all can be termed 21-row snakes if the rudimentary 4th row which extends to about the 12 th ventral be counted. They then could be termed 21-19-17 row snakes, but by present usage they are all 19-17 row snakes since a rudimentary or midbody row is seldom noted. This fact shows the advisability of giving the first count as the maximum midbody count and so stating or explaining definitely any other system used.

Dr. Dunn has this to say: "It is a general characteristic of Xenodontine snakes to reduce from midbody by dropping paravertebrals; of Natricine and Colubrine snakes to reduce from midbody maximum by dropping laterals. There is lots of evidence as to this in many genera and species. What happens on the neck is as yet not widely known, nor for many forms. It would be interesting to know more and the odd U. S. N. M. 27,980 is interesting."

\section{Scale rows of the U.S.N.M. specimens}

Disregarding the short neck rows it will be remembered that the Soledad series dropped the 9 th row at 100 plus or minus ten. The 6 U. S. N. M. 19-row specimens drop the 9th or paravertebral row at from the 90th to the $123 \mathrm{rd}$, averaging 111 . The six 21 -row specimens present an entirely different picture. Instead of having an extended 4th row as one might expect, the 10th and 9th rows are dropped, the 10th at from the 52th to the 87 th, averaging 71 ; the 9 th at from the 116 th to the 142 nd, averaging 130 . Two of this latter six were irregular. No. 27,499 has irregular rows that appear and disappear in a most confusing way. In places this specimen can be counted as a 23 row snake. I have seen such examples in Natrix.

There may be two species of 21-row snakes; one with extended fourth row which drops at about midbody and the 10th somewhat farther back; another species which drops the 10th and 9th. If these two forms do exist the female of each may be a 21 -row and the male a 19-row form.

\section{Errors possible in counting rows}

The spinal row starts several scales behind the parietals and disappears a few scales anterior to opposite the vent. A count just anterior to the vent might result in an even number which would not be a true count. Occasionally there is a short row near the vent between rows 2 and 3 or 3 and 4 , which, if counted would give a count of two too many. Frequently 
a row is dropped as much as 10 scales anterior or posterior to its mate on the opposite side. This usually accounts for the even-number counts frequently seen. The writer remembers one Natrix in which a row on one side was represented only by two small scales and a third which appeared at a short distance.

An example is U. S. N. M. 27,980. Wood lists this snake as having 20 rows. This snake drops the $4 \mathrm{R}$ at 72 , the $4 \mathrm{~L}$ at $18 ; 10 \mathrm{R} \& \mathrm{~L}$ at about 129 . Thus it has 21 rows from 1 to $18 ; 20$ rows 18 to $72 ; 19$ rows 72 to $129 ; 17$ to vent. Loveridge calls it a 21-row snake; Dunn (letter Nov. 24, 1944) and Dr. L. M. Klauber call it a 19-row snake with an abnormally long $4 \mathrm{R}$.

Since the "usual counting place" is half way between snout and vent, when a species of snake having a spinal row counts out an even number, the cause should be discovered and the explanation given. An even number is probably caused by an abnormality.

DATA ON SOLEDAD AND U. S. N. M. SPECIMENS

\section{Size and proportions}

The females appear to be larger judging by this series and the Cayman Island species. The tails are proportionately shorter than the males and the young have tails proportionately shorter than the adults.

\section{Secondary sexual differences}

Males are smaller, have shorter bodies with fewer ventrals; longer tails with more caudals; predominate with a single loreal; have greater proportion of preanal sutures; have heavier keels and striations and when mature have knobs on chin scales and near vent. The female has a greater proportion of 3 preoculars and has more acute abnormalities than the male.

In all specimens recorded by Wood every one with 21 rows or with preoculars 3-3 is a female, but he does not stress this fact. The only specimen Wood lists with 21 rows that he does not list as a female is his p.8; "U. S. N. M., No. ?, 21 rows, sex ?" Miss Cochran kindly furnished the number as 27,499 and the sex, female.

\section{The anal and preanal}

The anal and frequently the preanal is divided by a diagonal suture running forward from the snake's right to left. The direction of this diagonal in this species is invariable (Grant, 1944). There is occasionally a half ventral entering from either side immediately anterior to the anal or preanal or between the two.

The anal region is modified in $58 \%$ of males and only $16 \%$ of females. This discrepancy seems to have a direct sexual significance and might be considered in the category of secondary sexual dimorphism. The $12 \mathrm{U}$. S. 
N. M. specimens examined had no divided preanals, but only two were males.

A divided anal, preanal or a half ventral in this region is preceded by a pointed ventral, the point tending to protect the suture. This may be an indication of how important for survival it was for snakes to develop single ventrals.

Males with split preanals seem otherwise normal, but one of the two females thus split seemed to be generally abnormal, having abnormal loreals and temporals and she was the only specimen in the whole series with three postoculars in addition to having an extra half ventral.

\section{Certain scales nearly free from abnormalities}

The frontal, prefrontals, internasals, parietals, rostral, mental and chin shields show practically no abnormalities. In two cases the corner of the prefrontal enters the orbit and this might be considered as a fusion of that scale with the preocular. The posterior angle of the frontal is subject to considerable variation in outline. The supraoculars occasionally seem to fail to pinch off the uppermost preoculars on one side.

\section{Scale abnormalities}

Head abnormalities are more numerous in females. Omitting the labials there are $26 \%$ male and $60 \%$ female abnormalities; including labials there are $60 \%$ male and $180 \%$ female abnormalities. The term "abnormality" used here could be supplanted by "unusual" or in some cases "supernumerary".

Individual variations in tabular form

\begin{tabular}{|c|c|c|}
\hline & 34 males & 25 females \\
\hline \multirow{2}{*}{$\begin{array}{l}\text { Loreals.... } \\
\text { times oc- } \\
\text { curring. }\end{array}$} & $1-1,1-2,2-2$ & $1-1,1-2,2-2,2-3$ \\
\hline & $23 \quad 4 \quad 7$ & 10 \\
\hline \multirow{2}{*}{$\begin{array}{l}\text { Preoculars } \\
\text { times oc- } \\
\text { curring. }\end{array}$} & $1-1,1-2,2-2,2-3,3-3,4-4$ & $2-2,2-3,3-3,4-4$ \\
\hline & $\begin{array}{llllll}1 & 1 & 8 & 11 & 12 & 1\end{array}$ & $\begin{array}{lll}4 & 1 & 19\end{array}$ \\
\hline Ventrals... & $150,1,2,3,4,5,6,7,8,9,160,1,2,3$ & $156,7,8,9,160,1,2,3,4$ \\
\hline & $\begin{array}{lllllllllllllll}1 & 1 & 1 & 2 & 9 & 5 & 3 & 4 & 4 & 3 & 0 & 0 & 0 & 1\end{array}$ & 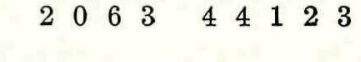 \\
\hline Caudals... & $\begin{array}{l}2 \text { broken not counted } \\
60,1,2,3,4,5,6,7,8,9 \\
1685423021 \\
\text { average } 63.5 ; \text { range } 9\end{array}$ & $\begin{array}{l}4 \text { broken not counted } \\
48,9,50,1,2,3 \\
147414 \\
\text { av. } 50.7 ; \text { range } 5\end{array}$ \\
\hline
\end{tabular}

Note actual gap of seven counts between sexes in caudals and that females have more ventrals and fewer cuadals. 


\section{Labial variation}

Small triangular scales are wedged between the lip-corners of certain labials. Their shape and position give no clue that they were derived from either of the adjacent labials. Normally there are 8 upper and 10 lower labials. Of 34 males 9 had 11 irregularities; of 25 females 13 had $32 ; 26 \%$ males and $52 \%$ females had irregularities; irregular males averaged 1.22 irregularities; females, 2.46 . Nearly $50 \%$ of irregularities were between the 4 th and 5th lower labials.

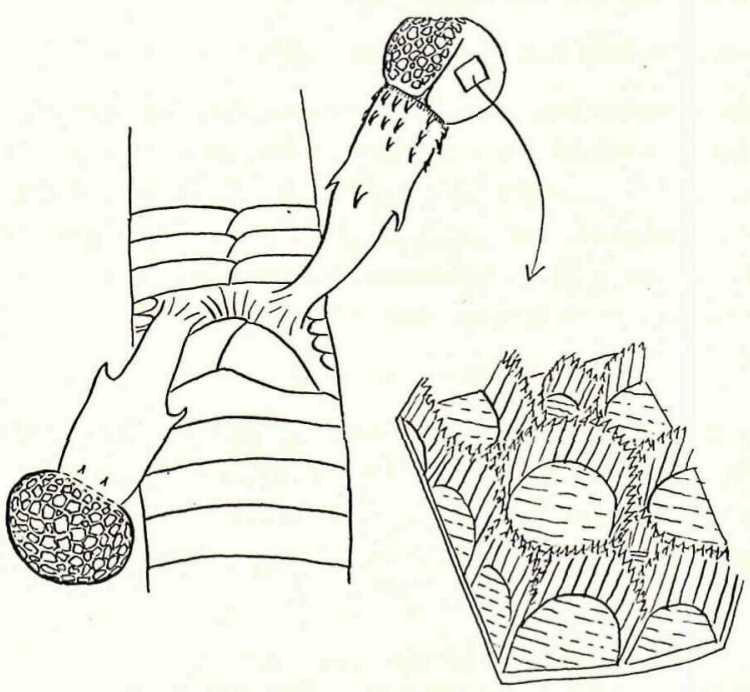

FIG. 2

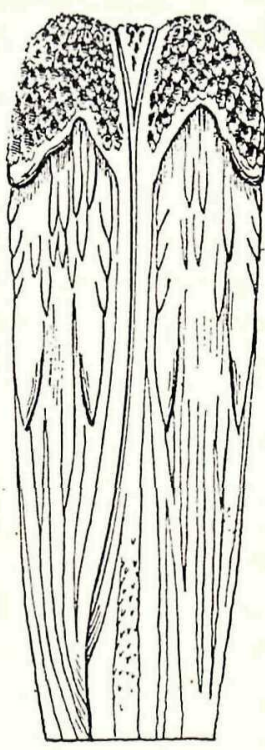

FIG. 3

FIg. 2. Hemipenes of freshly killed Tretanorhinus v. variabilis, injected.

FIG. 3. Hemipenes of Tretanorhinus v. variabilis drawn from a dissection, after Cope, Report of U.S.N.M., 1898, Plate 23, fig. 11.

\section{Hemipenis}

The drawing of the hemipenis herewith was made from specimens in which the organ was injected with alcohol immediately after death. This engorges the organ to such an extent as to hide the sulcus. (Fig. 2). Cope's fig. 11 of plate 23, shown as Fig. 3, was probably made from a dissection. Each figure shows characters not shown in the other.

\section{Color pattern and variation}

The venter ranges from cream through various degrees of pigmentation to almost solid slate in different individuals. The dark color displaces the light by dendritic patterns. There is a dark or nearly black line at the 
juncture of ventrals and first row. This line may not be apparent when the venter is dark. A light band occupies the remainder of the first, all of the second and part of the third rows. This band may be greatly reduced by pigmentation or may be chocolate. From the upper part of the third row the true dorsal pattern begins. Fundamentally it consists of about thirty cross bars nape to vent; twelve on tail. The bars occupy one to three

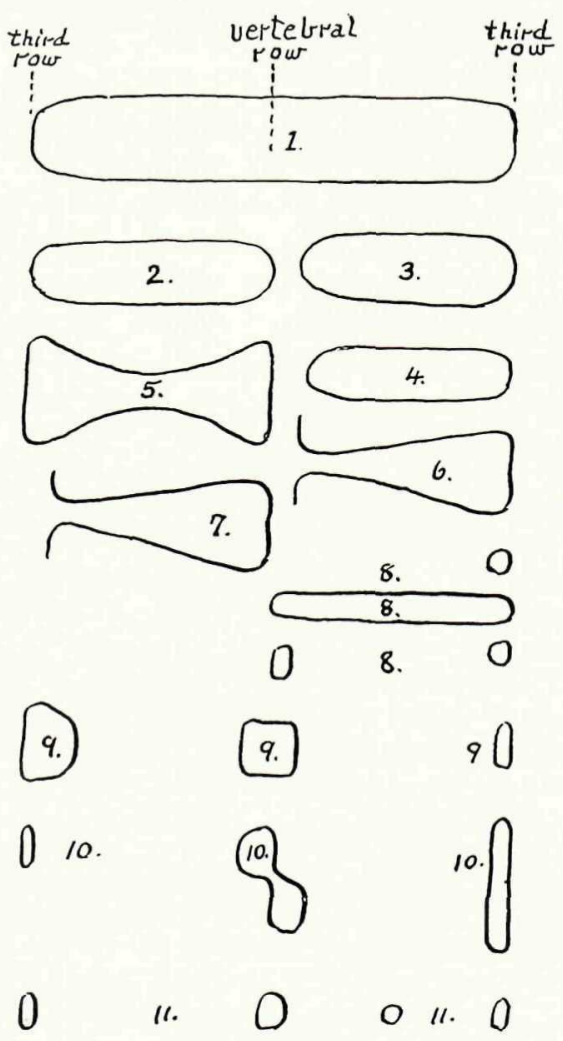

FIG. 4. Diagrammatic drawing of the various color patterns found on Tretanorhinus $v$. variabilis.

scales in width, separated by three to five scales; bars are occasionally outlined by light and there may be false shadow-bars between them. No specimen has been seen that adheres to any one dorsal pattern for its entire length. The most common variation is for the pattern on the two sides to alternate. Considering the bars on one side: they may narrow at the middle and widen at the ends becoming hour-glass shaped; they may separate, the upper part remaining a spot or coalescing with its mate on the 
opposite side forming a saddle; the lower part may remain a spot, but it usually forms a dash of various lengths and in one case a continuous wide stripe; the spots and bars may alternate; the spinal may be clear or have an occasional fleck or it may be black and the bars may touch it or not; the pattern may be reduced to occasional flecks on spinal, mid-side and third row. There may be combinations of these patterns on various parts of the body, but the predominately spotted patterns are confined to the males.

It is not a simple matter to count the bars from neck to sacrum. It is doubtful whether two students would obtain the same counts in a series of specimens.

As is to be expected, the pattern is more clearly defined on young specimens, but does not change in any way with growth. It does become obscured to varying degrees by added pigment. Another change that comes with maturity in many cases is a chocolate pigment which appears on the first three rows or the lateral stripe. The background is rarely chocolate.

Patterns expressed in their simplest terms, by sexes, taken at the vicinity of the 100th ventral:

\begin{tabular}{|c|c|c|}
\hline Pattern & male & female \\
\hline 1. simple bars $\ldots \ldots \ldots \ldots \ldots \ldots \ldots \ldots \ldots \ldots \ldots \ldots \ldots$ & 8 & 8 \\
\hline 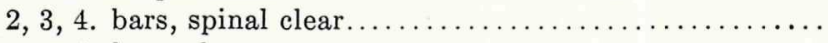 & 0 & 1 \\
\hline 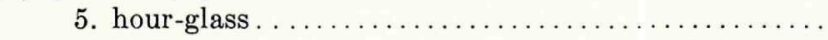 & 13 & 12 \\
\hline 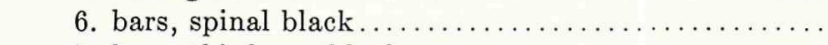 & 2 & 1 \\
\hline 7. bars, third row black......................... & 1 & 0 \\
\hline 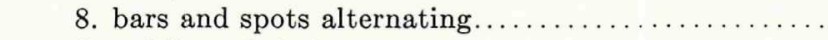 & 1 & 3 \\
\hline 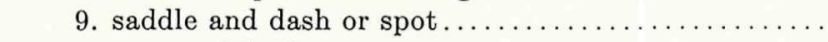 & 2 & 0 \\
\hline 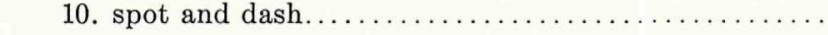 & 6 & 0 \\
\hline $11 . \operatorname{dots}$ only $\ldots \ldots \ldots \ldots \ldots \ldots \ldots \ldots \ldots$ & 1 & 0 \\
\hline
\end{tabular}

Dr. Oliver kindly read this MS and challenged this sentence by saying; "Isn't obscurity a change?" Yes, obscurity is a change in degree of pigmentation, but my meaning is a change in pattern such as spots growing into bars etc. during growth of the individual.

As to patterns I believe that possibly the primordeal coloration of many animals was a plain dark dorsum grading into a lighter venter. This is the simplest pattern and could be considered to consist of two longitudinal stripes - an upper and a lower color. This pattern gradually became more complicated and in turn the more numerous stripes broke up into checkered patterns and these in turn coalesced into cross bars by the process of natural selection. I do not believe that a pattern ever migrates on an individual. Slow moving snakes and animals and/or the young of fast moving adults may be spotted or barred. In the first instance the bars are permanent; in the second they are retained while useful. A pattern 
that fades out is usually replaced by a solid color, but in the case of Sphaerodactylus cinereus Wagler, the cross bands of the young are replaced by fine dots on a gray ground. The design has not migrated; it faded out and was followed by another. In some sexually mature male Pseudemys sp. we find a migration of dark pigment towards the sutures leaving the centers of the scutes light. Again it is not a pattern migration since the true pattern of ocelli, when present, does not move or change other than to fade. Neither do we consider this last case to be melanism as Barbour chooses to call it; melanism being congenital.

Dr. Dunn states in letter $11 / 24 / 44$; "The general opinion is that spotted pattern precedes striped or ringed or uniform color in development and in phylogeny (cf. Zenneck, Zeichnung der Boiden). I do not wholly subscribe to the general opinion, but I have seen spotted young change into uniform adults and spotted young change into striped adults, and spots in the embryo which are stripes at hatching. It certainly happens in development. I refer specifically to Elaphe quadrivittata, Lampropeltis rhombomaculata and Leimadophis bipraeocularis (whose 11 month development in the egg I followed in Bogota). The question is whether development implies anything as to phylogeny as general opinion says it does?"

Dunn does not make it clear whether he refers to the disappearance of a pattern which is followed by another, or whether there was a true migration of a pattern or part of a pattern.

The color patterns of my series may be expressed sexually: males have about $70 \%$ barred and $30 \%$ spotted pattern whereas the females are $100 \%$ barred. The male venters are 26, 53 and $21 \%$ light, medium and dark respectively whereas the females have 28,64 and $8 \%$. There is a natural correlation between spotted pattern and light venter; the spotted pattern requiring less pigment than the barred patterns.

Migration of pattern with growth was considered by Barbour who says (1919, p. 193): "In the young also the dark cross bands appear as oblong or squarish dorsal patches which become extended into strap-like bands with increasing age." I have four very young specimens which bear the entire strap-like bands and not the squarish dorsal patches, and adults which bear the squarish dorsal patches. I know of no snakes in which the markings spread with growth. In this and many other species the pattern tends to become dim or almost obliterated by an increase of dark pigment, but the basic pattern remains unchanged. In the common blue racer, Coluber sp., the young have a pattern of cross bars which fade out as the snake grows, but the pattern does not change shape or move.

On the same page Barbour quotes Boulenger as saying: “ . . . a more or less distinct light lateral streak on the second and third rows of scales ..." to which Barbour replies: "The white lateral band, he mentioned is always found in the young, but we have never observed it on adults." 
The characters which Wood uses as of subspecific value are; (1) color of venter, light or dark; (2) 2 or 3 preoculars; (3) spots or crossbars; (4) 19 or 21 scale rows.

The Soledad series shows the light or dark belly to be purely an individual variation and I believe that it is probably so in other localities. The matter of 2 or 3 preoculars seems to have a sexual significance in all specimens listed by Wood as well as the Soledad series. I attribute the predominance of 3 preoculars in females to the fact that they are the larger sex and heavier headed. The Soledad series seemed to show that spots were strictly a male pattern, but the U. S. N. M. specimens seen by me seem to disprove this assumption. Larger series are needed to settle this point. 19 or 21 scale rows is apparently diagnostic and it would be of interest to know whether a large series would still show the 21 rows confined to females. Data showing where 20 and 19 row populations intergrade would be of value in defining subspecies.

Every specimen in Wood's paper with 21 rows is a female; every specimen with preoculars 3-3 is a female.

Dr. Dunn Nov. 24, 1944 writes; "Wood described no new forms, but made a tentative allocation of a number of existing names. Your big Soledad series has pretty much eliminated his ventral color characters and his preocular characters. There is left the occurrence of 21 scale rows in the west-nearest to 21-row nigroluteus of the mainland-and perhaps more spotting and less crossbarring in the west-nearest to the never-barred nigroluteus of the mainland. He helped open the situation for discussion by showing that 21 row snakes were not confined to the Isle of Pines, but also occured in Pinar del Rio."

\section{SUMMARY}

Little is known about Tretanorhinus from Cuba. Individual variation is so considerable that a large series and extensive collecting will be necessary before any definite picture can be formed.

It appears that the number of caudals, pattern, color, preoculars, number of scale rows and possibly the sequence in which the rows are dropped have either taxonomic or sexual significance or both.

There probably is a salt or brackish water form common to Cuba, the Isle of Pines and surrounding islets. This form is probably at present represented in museum collections, but unidentified. The fresh water form has doubtless speciated considerably. The genus seems to be very plastic.

From our present knowledge the following forms appear to be recognizable:

T. v. wagleri (Jan): fresh water of the Isle of Pines and western Cuba; a long tailed form with 21 scale row females; ten more caudals than T.v.v. 
T.v. variabilis D. \& B.: fresh water from eastern Cuba; 19 rows; caudals male 70 , female 54 .

T. gaigeae, sp nov.: a light gray spotted form, probably confined to brackish water.

\section{ACKNOWLEDGEMENTS}

Dr. L. M. Klauber was generous with his library and his time; Mrs. H. T. Gaige and Dr. James A. Oliver read the MS and gave valuable advice; Dr. E. R. Dunn went over the MS painstakingly and gave much valuable help; specimens were kindly loaned by Dr. Thomas Barbour and Dr. Doris Cochran who also furnished data on other specimens; Mr. Loveridge also furnished some much needed data. Mr. Charles Shaw kindly sexed some specimens.

\section{LITERATURE CITED}

Amaral, Afranio do. 1929 Estudos sobre ophidion neotropicos. 17. Valor systematico de varias formas de ophidion neotropicos., Mem. Inst. Butantan. 4. pp. 1-68.

Barbour, Thomas. 1914 A contribution to the zoogeography of the West Indies, with especial reference to the amphibians and reptiles., Mem. M.C.Z., Vol. 44, pp. 207-359.

Barbour, Thomas. 1916 The reptiles and amphibians of the Isle of Pines., Ann. Carnegie Mus., Vol. 10, pp. 297-308.

Barbour, Thomas. 1937 Third list of Antillean reptiles and amphibians., Bull. M.C.Z., Vol. 82, pp. 77-166.

Barbour, Thomas and Charles T. Ramsden. 1919 The herpetology of Cuba., Mem. M.C.Z., Vol. 47, pp. 71-213.

Barbour, Thomas and Afranio do Amaral. 1924 Notes on some Central American snakes., Occ. Papers Boston Soc. Nat. Hist., Vol. 5, pp. 129-132.

Blanchard, Frank N. 1921 A revision of the king snakes: genus Lampropeltis., U.S.N.M. Bull. 114, pp. 1-260.

Bocourt, M. 1891-1895 Miss. Sci. Mex., Zool., 3, sec. 1, livr. 12-14, pp. 697-830.

Cope, E. D. 1900 The crocodilians, lizards and snakes of North America, Ann. Report Smithsonian Inst., 1898.

Duméril and Bibron. 1854 Erpét. Gén. Vol.7. p. 349.

Duns, E. R. 1939 Mainland forms of the snake genus Tretanorhinus. Copeia, pp. 212-217.

Grant, Chapman. 1935 Natrix sipedon sipedon in central Indiana, its individual and sexual variation., American Midland Naturalist., Vol. 16, pp. 921-931.

Grant, Chapman. 1937 The "midventral keel" in Testudinata., Proc. Ind. Acad. Sci., Vol. 36, pp. 246-252.

Grant, Chapman. 1940 The herpetology of the Cayman Islands., Bull. Inst. of Jamaica, Sci. ser. No. 2, pp. 1-65.

Grant, Chapman. 1944 Symmetry and asymmetry of the median sutures in reptilian scutellation., Herpetology., Vol. 2, No. 6, pp. 114-117.

Ruthyen, Alexander G. 1908 Variations and genetic relationships of the garter snakes, U.S.N.M., Bull. 61, p. 1-201.

Wood, G. Congdon. 1939 The genus Tretanorhinus in Cuba and the Isle of Pines., Proc. New England Zool. Club., Vol. 18, pp. 5-11. 